\title{
Sociedade civil online: diferentes usos da internet para fomentar a participação política
}

\author{
Civil society online: different uses of the internet to \\ improve political participation
}

\begin{abstract}
Diógenes Lycarião $^{[a]}$, Rafael Cardoso Sampaio ${ }^{[b]}$
[a] Doutorando e bolsista Capes pelo Programa de Pós-Graduação em Comunicação Social da Universidade Federal de Minas Gerais (PPGCom-UFMG), membro do grupo de pesquisa Mídia e Esfera Pública (EME) Belo Horizonte, MG - Brasil, e-mail: dramarc_leon@yahoo.com.br

${ }^{[b]}$ Doutorando e bolsista CNPq pelo Programa de Pós-Graduação em Comunicação e Cultura Contemporâneas da Universidade Federal da Bahia (PósCom-UFBA), membro dos grupos de pesquisa Comunicação, Internet e Democracia e Grupo de Estudos de Políticas de Informação, Cultura e Comunicações (GEPICC), Salvador, BA - Brasil, e-mail: cardososampaio@yahoo.com.br
\end{abstract}

\section{Resumo}

Este artigo busca analisar diferentes tipos de participação política e correlacioná-los com diversas oportunidades e obstáculos enfrentados pela sociedade civil quando esta utiliza a internet com fins políticos. Buscamos evidenciar que a internet pode não resolver por si os déficits democráticos, mas que determinados padrões de utilização por parte de atores coletivos tendem a gerar ganhos no sentido de organização, operacionalização de ações coletivas e efeitos de esfera pública. Esses efeitos foram identificados em função de três tipos de participação política: (1) tentativa indireta de influência, produzindo a proteção de direitos; (2) participação direta e (3) debate público. Os referidos efeitos acabariam por enviar ao sistema político pressões que reforçariam a responsividade em relação à esfera civil, assim como a legitimidade das decisões políticas.

Palavras-chave: Internet. Participação política. Esfera pública.

\section{Abstract}

This article accomplishes a synthetic exploration of the internet's political effects in relation to some types of use for the ITC promoted by civil society. These effects were established based on three types of political participation: (1) indirect attempt of influence, producing accountability and protection of interests; (2) direct participation and (3) public debate. This paper analyzes those different types of political participation and correlates them with the different types of use that appear in the reality of digital communication. This way, we aim to highlight that specific uses of the internet tend to generate different and mutually dependent advantages producing larger levels of political legitimacy in the political system.

Keywords: Internet. Political participation. Public sphere. 


\section{Introdução}

Dentro da avalanche de pesquisas acerca das implicações democráticas da internet, é possível observar, desde o início do debate, uma miríade de abordagens analíticas. No entanto, parece que, num primeiro momento, sobressaiu-se um sotaque mais "triunfalista" sobre os diversos potenciais discursivos e interativos que a web oferecia. Ela foi considerada, nessa tendência de análise, como uma solução para todas as patologias ou insuficiências que poderiam ser identificadas sobre o sistema político. No entanto, com a mesma velocidade de expansão dessa tecnologia da informação e da comunicação, a euforia foi cedendo espaço ao ceticismo e à ponderação, já que poucas mudanças estruturais foram sendo percebidas no sistema político e na sociedade civil. Isso não evitou, por outro lado, que a internet continuasse interessando a diversos pesquisadores, agora numa preocupação mais voltada a pensar os diferentes efeitos políticos que decorreriam de seus diversos tipos e contextos de uso (OBLAK, 2002; SALTER, 2004; STEFFEN, 2004).

Este artigo almeja contribuir para esse esforço de pesquisa a partir da proposta de tratar diferentes tipos de participação política e correlacioná-los com os distintos tipos de uso que se apresentam na realidade efetiva dos meios de comunicação digitais. Nesse sentido, na primeira seção deste trabalho, buscamos apresentar três tipos de participação política:

1) a tentativa indireta de influência dos cidadãos sobre o sistema político, buscando a accountability e a proteção de interesses;

2) a participação direta dos cidadãos, o que geraria resultados políticos mais justos, além do autodesenvolvimento dos participantes, e

3) a discussão política, a qual visaria ao entendimento mútuo entre os cidadãos de modo a processar legitimidade sobre as decisões políticas.

$\mathrm{Na}$ segunda seção, buscamos relacionar essas três formas de participação com quatro formas possíveis de utilização da internet por associações cívicas: a) interpretação de interesses e construção da identidade coletiva;

b) constituição da esfera pública;

c) ativismos políticos, embates institucionais e partilha de poder;

d) supervisão e processos de prestação de contas.

Buscaremos evidenciar que esses usos apresentam diferentes contribuições para a participação política. Contribuições essas que se diferenciam tanto pelo efeito político que geram como pela própria concepção democrática que descreve e procura ampliar tais efeitos.

Desse modo, nosso argumento é que esses usos da internet, especificamente, tendem a gerar ganhos no sentido de organização, operacionalização de ações coletivas e maiores níveis de legitimidade política de um Estado democrático.

\section{Tipologias de participação política}

Uma democracia, para que funcione bem, necessita de várias formas de participação política por parte dos cidadãos, seja como indivíduos isolados, seja na forma de associações cívicas com diferentes perfis de atuação (MAIA, 2007). As políticas democráticas devem facilitar o envolvimento dos cidadãos, forjar consenso político pelo diálogo, desenhar e implementar políticas públicas, assegurando que todos os indivíduos se beneficiem das riquezas produzidas pela coletividade (FUNG; WRIGHT, 2001, p. 3). Desse modo, a participação política por parte dos cidadãos pode significar maior legitimidade das decisões e das políticas públicas, além de uma maior eficácia na implementação destas (TEORELL, 2006; FUNG; WRIGHT, 2001; MARQUES, 2008). Mas o que se entende precisamente por participação política?

Em primeiro lugar, é preciso considerar que trabalhamos com uma visão ampla de "política", que não se restringe às instituições formais do Estado, mas com aquela que também engloba "os processos de associação cívica, negociação e luta entre os sujeitos nas interações do dia-a-dia" (MAIA, 2006, p. 15). Trata-se de uma abordagem que considera o contexto de movimentos sociais, que liga política a valores culturais, processos identitários e medidas de autoconfiança. 
Apesar da complexidade e das diversas teorias a respeito do conceito de sociedade civil, adotamos aqui a noção de esfera civil, a qual se refere aos cidadãos ordinários, às associações voluntárias, aos movimentos sociais e a outras formas de organização social, que se encontram fora do espectro do Estado e da economia (COHEN; ARATO, 1992; EDWARDS, 2004; MAIA, 2007).

Isso não quer dizer, por outro lado, que os cidadãos ordinários e os núcleos institucionalizados desempenhem os mesmos papéis na produção de influência política. Nesse sentido, se cabe a todos os indivíduos o direito de processar entendimentos e interpretações em iguais condições e chances de validar suas razões e interesses, caberia, nessa perspectiva, aos atores da sociedade civil organizada a realização de um trabalho dual com vistas à atualização dos modos e orientações da influência política da esfera civil sobre a esfera política.

Esse trabalho dual, no âmbito da teoria política, foi descrito por Cohen e Arato $(1992)^{1}$ quando estes atribuíram à sociedade civil a capacidade de realizar um tipo de ação que havia sido descrito, inicialmente, pelo pensador marxista Antônio Gramsci. Um tipo de ação que, ao ser adaptado pelos referidos autores a um marco teórico adequado a uma teoria política que se propõe a conservar os limites entre Estado e sociedade civil (algo que o projeto marxista ${ }^{2}$ visava a demolir), fez com que ele se apresentasse bastante útil para analisar o papel da sociedade civil no quadro das democracias contemporâneas. Um papel que, nesse sentido, ajuda a identificar fenômenos políticos para além do quadro institucional diretamente vinculado ao sistema político.
Por almejar incluir justamente essas dimensões alargadas da política que abrangem as diversas formas de atuação da esfera civil, utilizamo-nos do trabalho de síntese de Teorell (2006) para identificar os diferentes tipos de participação política que podem, e devem, apresentar-se num sistema político democrático consolidado. $\mathrm{O}$ autor identifica esses diferentes tipos de participação a partir de três grandes modelos de democracia que são, a saber, o responsivo (liberal), o participativo e o deliberativo. Como não é objetivo desse trabalho discutir, de maneira mais exaustiva, esses modelos democráticos, trataremos, então, de explorar, mais detidamente, os tipos respectivos de participação que são traçados a partir deles.

O primeiro modo seria pela tentativa de influência. Aqui, os cidadãos não determinam diretamente os resultados políticos, mas expressam suas preferências sobre as políticas do governo com o objetivo de tentarinfluenciá-las. O grande foco está na accountability, na prestação de contas dos governantes, que precisam estar atentos às necessidades de seus governados. Segundo Teorell (2006), tal participação leva a uma proteção dos interesses. Verba e Orren (1985, p. 182), em seus estudos sobre a igualdade na América, reforçam a importância dessa influência sobre os governantes: "A habilidade de influenciar o governo, de falar e ser ouvido, é um direito democrático fundamental. Sem alguma influência, pelo menos através do sufrágio, uma pessoa não é um cidadão por completo". ${ }^{3}$ Isso porque, se apenas uma pequena parcela da população tiver a capacidade de influência, a democracia tornaria-se-ia viciada e politicamente injusta.

1 Os autores assim definem a categoria de sociedade civil: "We understand 'civil society' as a sphere of social interaction between economy and state, composed above all of the intimate sphere (especially the family), the sphere of associations (especially voluntary associations), social movements, and forms of public communication" (COHEN; ARATO, 1992, p. 9). Tradução livre: "Nós entendemos 'sociedade civil' como uma esfera de interação social entre a economia e o Estado, composto, sobretudo, pela esfera íntima (especialmente a família), a esfera de associações (especialmente as associações voluntárias), movimentos sociais e as formas de comunicação pública”.

2 No entanto, não se pode encaixar as teses de Gramsci de modo simétrico ao marxismo tradicional. Conforme analisa Bobbio (1982), Gramsci trata-se de um pensador original dentro do pensamento marxista. Nesse sentido, uma de suas principais contribuições para a transformação do marxismo foi a proposta de compreender-se a sociedade civil "não mais [como] 'todo o conjunto de relações materiais', mas sim [como] todo o conjunto das relações ideológico-culturais [...]” (BOBBIO, 1982, p. 33). Não obstante isso, a perspectiva de retroagir o Estado na forma de uma sociedade politicamente autônoma e auto-organizada continua sendo uma linha de horizonte compartilhada por Gramsci em relação ao marxismo tradicional.

3 Em todo o artigo, faremos traduções livres dos trechos originais em inglês. 
Ao teorizarem sobre uma abordagem similar a esse tipo de participação política, ${ }^{4}$ Levine, Fung e Gastil (2005) falam da necessidade de encorajar e persuadir a sociedade política a dar atenção à participação da população. Para eles, são necessárias estratégias de dentro e de fora do Estado para que a sociedade civil possa influenciar de maneira mais sistemática a esfera da política formal. As estratégias internas buscam criar relações com os tomadores de decisão, ratificar requerimentos administrativos, ou legais, que incorporem as discussões públicas em suas decisões. Para esses autores, as "estratégias externas, por contraste, confiam em gerar pressão política e social para compelirem oficiais a responder os resultados da deliberação pública" (LEVINE; FUNG; GASTIL, 2005 , p. 277), muitas vezes utilizando-se dos meios midiáticos e/ou por meio de ações espetaculares.

A segunda forma de participação apontada por Teorell se dá pela presença e pelo controle direto dos cidadãos sobre parte do processo de decisão política. Nessa compreensão, são mantidas as estruturas representativas, mas de modo que sejam ampliadas as oportunidades de participação política fora do sistema representativo tradicional. A expansão dessas oportunidades teria por objetivo o desenvolvimento da autonomia política da população e de suas habilidades cidadãs:

a teoria da democracia participativa é construída em torno da afirmação central de que os indivíduos e suas instituições não podem ser considerados isoladamente. A existência de instituições representativas a nível nacional não basta para a democracia; pois o máximo de participação de todas as pessoas, a socialização ou 'treinamento social', precisa ocorrer em outras esferas, de modo que as atitudes e qualidades psicológicas necessárias possam se desenvolver (PATEMAN, 1992, p. 60).

Nesse modo de participação, os cidadãos tornam-se mais capazes de lidar com os problemas da sociedade à medida que vão participando. A participação seria benéfica (educativa), já que haveria um efeito de preparação dos cidadãos na aquisição das habilidades e competências necessárias a uma efetivação da vontade política sobre o âmbito de tomada das decisões políticas.

Pode-se ainda afirmar que esse tipo de participação, ao promover a interação direta dos cidadãos, aumenta a accountability e reduz a distância, entre governo e cidadãos, que é criada pelas instituições políticas intermediárias. Nesse caso, quando os participantes têm a oportunidade de exercer alguma autoridade, o custo da participação tende a ser bem menor. Como resultado, as estratégias e soluções públicas dos atores civis podem vir a mostrar-se mais adequadas que aquelas de burocratas, principalmente em relação às políticas públicas locais. Isso tendo em vista que são justamente os usuários dos serviços públicos aqueles que tendem a possuir um conhecimento mais sensível às condições locais que impedem que tais serviços atendam às necessidades dos cidadãos. Ademais, sendo eles mesmos os mais interessados na sua boa execução, poderão, com mais rapidez e eficiência, monitorar a corrupção e a irresponsabilidade que eventualmente ocorrem na máquina estatal (FUNG; WRIGHT, 2001; FUNG, 2004).

Já o terceiro formato de participação definido por Teorell (2006) é a discussão política. O objetivo aqui é produzir a formação da opinião e da vontade públicas de maneira atrelada ao processo de tomada das decisões políticas. Nesse sentido, os resultados dessas decisões devem ser precedidos por um tipo de discussão em que todos os argumentos ou discursos sejam ouvidos e pesados (DRYZEK, 2004; HABERMAS, 1997; TEORELL, 2006).

A principal consequência desse modelo de participação seria a legitimidade intersubjetiva. Essa legitimidade formaria-se a partir de uma responsividade do sistema político em relação à contestação discursiva operada na esfera pública (DRYZEK, 2004). Nesse caso, o sistema político possui o papel também de garantir, por meio dos procedimentos institucionais de decisão política, a igualdade política na participação discursiva, i.e. que todos os argumentos de cada lado contestador sejam levados em conta.

Enfatiza-se, nesse tipo de interação, o processo de formação da vontade coletiva pela delibera-

\footnotetext{
4 No original, os autores tentam refletir sobre formas de fazer a participação deliberativa mais influente, entretanto, nesse momento, os autores pensam a participação apenas no sentido de tentativa de influência e não sob a ideia de esfera pública, que desenvolveremos ao longo do texto.
} 
ção pública (HABERMAS, 1999). Sobre as vantagens desse tipo de participação política, destaca-se que:

decisões resultantes da deliberação podem ser mais justas elegítimas porque resultam de razões ao invés de vantagens arbitrárias. Elas podem ser mais sábias porque permitem que um espectro amplo de perspectivas e informações sejam sondadas conjuntamente. As discussões podem auxiliar os indivíduos participantes a aclarar suas próprias visões (FUNG, 2004, p. 179).

Ao observar-se essa forma de interação em comparação com as demais, é possível perceber que existem grandes diferenças de como cada uma compreende o processo que deve abarcar a participação. Não obstante, existe um elo comum a todas essas formas, que é, a saber, a constituição de responsividade da esfera política em relação à esfera civil. Sobre essa questão, há uma vasta literatura apontando que os sistemas políticos contemporâneos mostram-se poucos responsivos às perspectivas, vontades e atribuições que são próprias da esfera civil em um Estado efetivamente democrático.

$\mathrm{Na}$ visão de diversos autores, faz-se, então, necessária a inclusão de novos mecanismos de participação política que tenham a expectativa realista de influência e ampla abertura para uma discussão informada entre os cidadãos. Nesse sentido, há uma vasta literatura que aponta a internet como algo capaz de contribuir com essas metas. Tratemos, então, das oportunidades específicas oferecidas pelos diversos tipos de uso da internet em relação a tais finalidades. Nessa exploração, apontaremos como, a depender do tipo de uso perpetrado pela esfera civil, um tipo diferente de participação política é incrementado. Nosso argumento é que os usos que promovem as formas de participação anteriormente identificadas podem articular-se de modo a formar um complexo de ações integradas. Ações essas que, ao aprimorarem os diversos mecanismos de interação política possíveis de uma democracia, tendem a gerar maior responsividade da esfera política em relação à esfera cívica.

\section{Formas de utilização da internet em relação aos modelos de participação política}

$\mathrm{Na}$ literatura que envolve a correlação entre internet e participação, há uma diversidade de hipóteses que tenta dar respostas quanto aos efeitos globais que essa tecnologia da comunicação estaria produzindo sobre o modo como os cidadãos se relacionam com o poder político. ${ }^{5}$

Não obstante, compartilhamos da análise de que muitas das premissas que constituem essas hipóteses fundam-se em acepções teórico-metodológicas problemáticas. Ao se constatar que as oportunidades e os empreendimentos de participação política operados na internet podem apresentar grandes discrepâncias em termos de efeitos - a depender do contexto e da ação efetiva que os diferentes agentes políticos realizam -, observa-se que um crescente volume de análises tem sublinhado a necessidade de uma guinada teórico-metodológica na pesquisa que trata dos efeitos políticos da internet (OBLAK, 2002; SALTER, 2004; STEFFEN, 2004; WRIGHT; STREET, 2007). Essa guinada passa, então, a colocar de lado as abordagens mais globais acerca desses efeitos e passa a preocupar-se em identificar os diferentes contextos, aspectos tecnológicos e usos da internet para promover a participação política. A diferenciação desses aspectos permitiria, assim, identificar quais desenhos participativos são próprios ou não aos padrões normativos estabelecidos pelos diversos valores e modelos democráticos.

Em consonância com essa orientação teórico-metodológica, Maia (2007) apresenta, então, quatro formas de uso específicas que, se analisadas mais detidamente, apontam para resultados políticos que podem ampliar a participação política nos termos de uma maior responsividade entre esfera civil e esfera política. Para verificar quais usos realizam essa ampliação, e como o fazem, iremos apresentálos e buscar traçar um paralelo com os modos de participação identificados por Teorell (2006), de maneira a evidenciar os ganhos democráticos que cada tipo de uso implica.

\footnotetext{
5 Marques (2008), ao analisar os canais de participação oferecidos pelos sítios na internet, da Câmara dos Deputados e do Executivo nacional, faz uma longa e ponderada revisão a respeito de internet e participação política, considerando os diversos fatores para sua implementação do ponto de vista institucional.
} 
Em primeiro lugar, a autora aponta que a internet pode ser usada para a interpretação de interesses e a construção de identidades coletivas, ou seja, para que os indivíduos "expressem e atualizem suas identidades, valores e interesses" (MAIA, 2007, p. 49). Nesse uso da rede pelos movimentos civis não se pode falar propriamente em participação política. $\mathrm{Na}$ verdade, há uma busca entre os próprios atores da esfera civil na construção de suas identidades, interpretação de sua situação em relação a outros atores sociais, assim como a busca em construir novos padrões de autoapresentação e reconhecimento (MAIA, 2007). Certamente, esses novos padrões podem estabelecer um rearranjo das malhas interpretativas que sustentam as políticas em relação a determinados grupos identitários e, assim, possivelmente modificar também essas políticas.

Contudo, não se pode identificar um elo sempre evidente e necessário entre a reconfiguração de padrões identitários e a introdução de processos participativos que visem a reconfigurar políticas públicas. Desse modo, Bentivegna (2006) expressa como os conflitos que envolvem a disputa de sentido em torno de certas identidades possuem apenas a potencialidade de estabelecer um movimento de influência política entre esfera civil e esfera política.

Um exemplo que expressa bem essas fronteiras - que podem ou não ser ultrapassadas de modo a manifestar participação política - dá-se em relação aos sítios voltados aos moradores de favelas. Enquanto há aqueles que se especializam em reconstruir autorrepresentações da população moradora de favelas (www.olharesdomorro.org), há outros que também se voltam a divulgar informações e campanhas que promovem direitos e melhorias à população desse tipo de ocupação urbana (www. anf.org.br). Caso essa divulgação consiga gerar uma mobilização política em termos de pressão política, poder-se-ia, então, verificar processos participativos com efetividade sobre o sistema político.

O segundo uso da internet identificado por Maia (2007) é a "constituição de esfera pública". Trata-se da discussão política proposta por Teorell (2006). Aqui, as preferências e necessidades não são fixas, mas constituem-se na relação com outros participantes. Nesse caso, a internet é utilizada como um palco para a discussão pública online (ALBRECHT, 2006; DAHLBERG, 2007; MIN, 2007), para reconfigurar os padrões de acessibilidade da discussão política e para ampliar a densidade argumentativa da visibilidade pública política (LYCARIÃO, 2010).

No que diz respeito à discussão política online, as referidas pesquisas fornecem estudos de caso que permitem verificar como há situações em que a internet pode servir como um ambiente adequado para "preparar os cidadãos e os atores coletivos cívicos para debates mais exigentes" (MAIA, 2008, p. 51) na esfera pública. Nesse caso, as associações cívicas engajam-se em atividades reflexivas e democráticas para testar ideias, imaginar novas ações e propor soluções alternativas para seus problemas. Esse tipo de discussão aumenta a qualidade dos julgamentos democráticos, reduz a arbitrariedade e a instabilidade dos mecanismos de agregação de preferências, além de conceder legitimidade aos procedimentos e resultados das decisões tomadas. A efetivação dessa discussão em um processo de participação política se dá quando os entendimentos e argumentos mobilizados na internet e na esfera pública como um todo, produzem uma resposta por parte do sistema político.

Já em relação às utilizações da internet que ampliam a acessibilidade e a densidade argumentativa da esfera de visibilidade pública, Lycarião (2010) aponta para a página do Greenpeace Brasil (http: / / www. greenpeace.org/brasil) como um exemplo relevante desse tipo de uso. O estudo desenvolvido argumenta que, por meio do âmbito digital de comunicação da entidade ambientalista, é possível perceber um tratamento discursivo dos problemas que ganham visibilidade no âmbito dos media com níveis mais densos e extensos de argumentação. Níveis extensos esses que, ao acompanharem de forma sincrônica a dinâmica de atualização da visibilidade acionada pelas ações espetaculares da organização, acabam configurando-se como fontes daquilo que o trabalho identifica como sistema informativo ampliado. ${ }^{6}$

A disponibilidade dessas fontes é vista como um elemento fundamental para a sustentação

\footnotetext{
6 A noção de sistema informativo ampliado, nesse caso, aparece como peça conceitual chave para entender o papel da internet na comunicação política contemporânea. Um papel que, nesse contexto, viria a facilitar a ação de edição dos materiais do sistema informativo para a montagem de debates públicos (GOMES, 1999). Essa edição se mostrava bem mais onerosa, principalmente com relação aos atores cívicos, que antes não tinham a internet para disponibilizar para a audiência da comunicação de massa um quadro completo e atualizado de suas opiniões acerca dos assuntos e problemas políticos em torno dos quais esses atores conseguem, eventualmente, conquistar visibilidade pública na mídia massiva.
} 
de debates públicos por parte do Greenpeace. Isso porque serão justamente esses âmbitos os recursos mais acessíveis e diretos que o público terá em mãos para se apropriar dos níveis mais densos de argumentação que a entidade ambientalista produz acerca das discussões tornadas visíveis pela comunicação de massa. Visibilidade essa que, no caso do Greenpeace, tem como um de seus elementos acionadores principais os recursos espetaculares de comunicação.

O terceiro uso da internet, identificado por Maia, é definido dentro de uma categoria que inclui "ativismo político, embates institucionais e partilha do poder". Se as duas primeiras possibilidades de uso estão muito próximas nos efeitos que provocam sobre o sistema político em termos de participação política, esse último, por outrolado, parece configurar um nível muito mais elevado de empoderamento da vontade cívica sobre as ações do aparelho administrativo do Estado. Isso porque, enquanto o ativismo e os embates institucionais referem-se às tentativas de influência da sociedade civil sobre o sistema político, as experiências de partilha de poder precisam necessariamente de uma ação liderada pelo Estado, de modo que este deverá conceder à esfera civil uma cota de poder vinculante sobre as decisões aí geradas.

Dessa forma, ao correlacionarmos esse terceiro tipo de uso identificado por Maia, podemos perceber que as duas primeiras possibilidades estão mais diretamente ligadas ao primeiro tipo de participação política explorado por Teorell. Já a terceira possibilidade correlacionaria-se à participação direta dos cidadãos (a terceira forma de participação do referido autor). Nesse caso, ainda são raros os exemplos de uma efetiva participação direta utilizando-se a internet.

Não obstante, um caso proeminente, no Brasil, foi o Orçamento Participativo Digital (OPD) realizado pela prefeitura de Belo Horizonte em 2006 e 2008. ${ }^{7}$ Nas duas edições do programa, os eleitores de Belo Horizonte escolheram, pelo ambiente online, as obras a serem realizadas pela prefeitura. Segundo o órgão executivo, o objetivo do programa era aumentar a participação dos diversos ramos da sociedade que usualmente não participam do orçamento participativo presencial. Sampaio (2009) avalia que o Orçamento Participativo Digital impactou em perdas na qualidade da deliberação pública e nos possíveis ganhos educacionais da discussão política - aspectos mais presentes no orçamento participativo regional, uma vez que os processos valorizaram a participação exclusivamente plebiscitária. Por outro lado, em relação à participação direta, o OPD foi bem-sucedido em aumentar a participação popular. Nas duas edições desse orçamento, o número de votantes pela internet foi de três a seis vezes superior ao número de presentes no orçamento participativo regional nos mesmos anos.

Peixoto (2008) evidenciou que não parece haver uma correlação entre os fatores socioeconômicos e os votos por regionais no OPD de 2006, como afirmariam as teorias de exclusão digital. Isso tendo em vista que os três bairros com maior votação em 2006 apresentavam baixos IDH em relação à média da cidade, mesmo não se tratando dos bairros mais populosos de Belo Horizonte. De tal forma que, apesar do OPD valorizar o empoderamento do cidadão - uma vez que ele vota diretamente na obra desejada -, há indícios de que as associações cívicas, especialmente as associações de bairros, detiveram grande força de mobilização durante as duas edições do programa.

Já em relação ao ativismo político e aos embates institucionais, podem-se destacar, como fenômeno recorrente, as petições online e as ações do assim chamado ciberativismo. Essa prática tem sido utilizada por diversas organizações, obtendo, entre elas, maior ou menor centralidade como tática política. Uma organização que estabelece as petições online como uma forma privilegiada de tentativa de influência política é a Avaaz. Essa entidade promove campanhas nos mais diversos eixos temáticos (direitos humanos, meio ambiente, democracia, etc.) e, para isso, coloca as petições e cartas online como uma forma de gerar um efeito similar ao que os abaixoassinados obtêm. Segundo o sítio da organização:

a tecnologia e a Internet permitiram que os cidadãos se conectem e se mobilizem como nunca

\footnotetext{
7 O OPD aconteceu completamente à parte do orçamento participativo presencial, possuindo sítio na internet, calendário e orçamento próprios. Os orçamentos participativos regional e habitacional de Belo Horizonte também não sofreram modificações estruturais pela realização do OPD.Até a conclusão deste artigo, a Net Serviços não havia disponibilizado a audiência do programa Sociedade, e o portal TVI ainda não havia fornecido o número de Page views.
} 
visto antes. [...] Avaaz trouxe essa tendência para a escala global, conectando pessoas além das fronteiras e trazendo uma nova voz para a política internacional que antes era inacessível para a população (AVAAZ.ORG..., 2009).

Como a maioria das iniciativas cívicas que possuem a meta de transformar ou implementar políticas públicas, seus efeitos podem ser identificados em função daquilo que se consegue gerar em termos de mobilização política e de respostas em relação aos atores e instituições interpeladas. Nesse sentido, tanto o número de assinantes das petições como as ações políticas de resposta por parte dos alvos dessas petições são elementos-chave para que se possa identificar uma tentativa de influência política com algum efeito relevante. Se a petição não ganha muitos adeptos nem consegue mobilizar a atenção dos atores interpelados, então não se pode falar propriamente em fenômenos participativos. Haveria, nesse caso, um engajamento político pontual sem maiores repercussões, pelo menos em um curto prazo.

Finalmente, o último uso da internet pelas associações civis descrito por Maia é "a supervisão e processos de prestação de contas". Aqui, a internet é utilizada para um controle mais qualificado e sistemático dos representados sobre seus representantes, uma vez que seu efeito é gerar uma maior acessibilidade e visibilidade de informações políticas, que muito provavelmente passariam despercebidas caso não houvesse esse trabalho. Esse é o caso do portal "Transparência Brasil" (www.transparencia.org.br), o qual, desde 2000, vem utilizando "instrumentos de Internet para propiciar o monitoramento do fenômeno da corrupção".

Com esses instrumentos, o portal Transparência Brasil tem obtido êxito em disseminar informações que visam a favorecer a fiscalização das ações do sistema político e de seus atores individuais. Sob essa perspectiva, a organização tem conseguido fazer com que essas informações adensem ainda mais as ações de responsabilização promovidas pela comunicação de massa. Uma evidência desse adensamento pode ser observada pela sistemática citação das informações produzidas pela entidade em diversos veículos de comunicação massiva. Nesse sentido, em uma única semana, o portal chegou a ser citado em 81 matérias dos diversos jornais indexados pelo Google News. ${ }^{8}$

Esse tipo de experiência de utilização da internet também pode ser correlacionado àquela forma de participação política, identificada por Teorell (2006), que se caracteriza pela tentativa de influência política. Buscam-se, portanto, accountability e responsividade por parte dos representantes, os quais, a partir do momento em que procuram maximizar suas chances de permanência no poder, tendem a estar atentos a essas tentativas e procuram estabelecer estratégias de construção de imagem pública que gerem no eleitorado a sensação de estarem agindo de acordo com as expectativas de seus representados.

Dessa forma, as associações cívicas podem coletar, organizar e disponibilizar informações sobre as ações dos políticos. Para Maia (2007, p. 54), a "aquisição de informação torna os indivíduos aptos a demandar transparência das instituições do governo e a exigir que dirigentes e representantes de outros poderes prestem conta de suas declarações e ações".

\section{Considerações finais}

Neste artigo, buscamos explorar os efeitos políticos da internet em função de alguns tipos de uso dessa tecnologia da comunicação, identificados por Maia (2007), no que se refere à sua operacionalização pela sociedade civil. Os referidos efeitos foram estabelecidos a partir de três tipos de participação política sistematizados por Teorell (2006).

Ademais, é preciso ter cautela com relação às consequências dos tipos de uso da internet ao gerar as formas de participação política aqui trabalhadas. Nesse sentido, a ampla informação da internet e o adensamento do sistema informativo como um todo não implicam uma geração automática de cidadãos mais bem informados e engajados.

Levando em conta as diferenças normativas que cada tipo de participação aqui explorado pode acionar, é preciso ter em vista que seus efeitos políticos, apesar de poderem gerar controvérsias acerca do nível e da intensidade de realização, não são mutuamente

8 Ver em: <http://news.google.com.br/news/search?um=1\&ned=pt-BR_br\&hl=pt-BR\&q=0 $\% 22$ Transpar $\%$ C $3 \%$ AAncia $+B r a s i$ 1\%22\&as_qdr $=$ w\&as_drrb=q\&cf=all $>$. Acesso em 26 ago. 2009. 
excludentes na vida democrática. Isso porque o próprio sistema democrático acaba por ser um arranjo em construção que vai sendo desenhado numa dinâmica em que esses modelos vão conseguindo, cada um a seu modo e com cota relativa de sucesso, influenciar a cultura política e a arquitetura institucional do sistema político (HELD, 1987).

É por isso então que não há problemas em correlacionar-se os diversos tipos de uso da internet praticados pela sociedade civil em função dos diferentes modos de participação política possíveis. No caso, não há problemas de natureza analítica, se essa correlação venha a ser produzida com o objetivo de apontar-se as possibilidades de uma maior responsividade entre esfera civil e esfera política.

Nesse sentido, faz-se mister frisar que não estamos afirmando que esses diferentes modos de participação são sequenciais ou gradativos, mas sim que eles podem e devem ser complementares. De diferentes maneiras, eles visam a demonstrar aos representantes e atores interpelados que há um custo político em potencial caso as demandas enviadas não sejam atendidas. O custo político mais evidente e poderoso é aquele mensurado nas competições eleitorais das sociedades democráticas contemporâneas: o voto.

\section{Referências}

ALBRECHT, S. Whose voice is heard in online deliberation? A study of participation and representation in political debates on the internet. Information, Communication \& Society, London, v. 9, n. 1, p. 62-82, 2006.

AVAAZ.ORG. Quem somos. Disponível em: < http:/ / www.avaaz.org/po/about.php>. Acesso em: 26 ago. 2009.

BENTIVEGNA, S. Rethinking politics in the world of ICTs. European Journal of Communication, v. 21, n. 3, p. 331-343, 2006.

BOBBIO, N. O conceito de sociedade civil. Tradução de Carlos Nelson Coutinho. Rio de Janeiro: Graal, 1982.

COHEN, J. L.; ARATO, A. Civil society and political theory. Cambridge, MA: MIT Press, 1992.

DAHLBERG, L. Rethinking the fragmentation of the cyberpublic: from consensus to contestation. New Media Society, v. 9, n. 5, p. 827-847, 2007.
DAHLGREN, P. The public sphere and the net: structure, space, and communication. Mediated politics. In: BENNETT, W. L.; ENTMAN, R. M. (Ed.). Communication in the future of democracy. Cambridge, UK: Cambridge University Press, 2001. p. 33-55.

The internet, public spheres, and political communication: dispersion and deliberation. Political Communication, v. 22, n. 2, p. 147-162, 2005.

DRYZEK, J. S. Legitimidade e economia na democracia deliberativa. In: COELHO, V. S. P.; NOBRE, M. (Org.). Participaçãoe deliberação:teoriademocráticaeexperiências institucionais no Brasil contemporâneo. São Paulo: Editora 34, 2004. p. 41-62.

EDWARDS, M. Civil society. Cambridge, UK: Polity Press, 2004.

FUNG, A. Receitas para esferas públicas: oito desenhos institucionais e suas conseqüências. In: COELHO, V. S. P.; NOBRE, M. (Org.). Participação e deliberação: teoria democrática e experiências institucionais no Brasil contemporâneo. São Paulo: Editora 34, 2004. p. 173-209.

FUNG, A.; WRIGHT, E. O. Deepening democracy: innovations in empowered participatory governance. Politics \& Society, v. 29, n. 1, p. 5-41, 2001.

GOMES, W.Esfera pública política e media II. In: RUBIM, A. A. C.; BENTZ, I. M. G.; PINTO, M. J. (Ed.). Práticas discursivas na cultura contemporânea. São Leopoldo: Ed. Unisinos, 1999.

HABERMAS, J. Direito e democracia: entre facticidade e validade. Rio de Janeiro: Tempo Brasileiro, 1997. v. 2.

HABERMAS, J. O espaço público, 30 anos depois. Caderno de Filosofia e Ciências Humanas, Belo Horizonte, ano VII, n. 12, p. 7-28, 1999.

HELD, D. Models of democracy. Palo Alto, CA:Stanford University Press; Cambridge, UK: Polity Press, 1987.

LEVINE, P.; FUNG, A.; GASTIL, J. W. Future directions for public deliberation. In: GASTIL, J. W.; LEVINE, P. (Ed.). The deliberative democracy handbook: strategies for effective civic engagement in the twenty-first century. San Francisco: Jossey-Bass, 2005. p. 271-288.

LYCARIÃO,D. B. S. Greenpeace, espetáculo e internet: o intercruzamento entre diferentes modos de comunicação para a sustentação de debates na esfera pública. 2010. 150 f. Dissertação (Mestrado em Comunicação Social) - Universidade Federal de Minas Gerais, Belo Horizonte, 2010. 
MAIA, R. C. M. Mídia e vida pública: modos de abordagem. In: MAIA, R.; CASTRO, M. C. P. S. (Org.). Mídia, esfera pública e identidades coletivas. Belo Horizonte: Ed. UFMG, 2006. p. 11-62.

MAIA, R. C. M. Redes cívicas e internet: efeitos democráticos do associativismo. Logos, Rio de Janeiro, v. 14, n. 27, p. 43-62, 2007.

MAIA, R. C. M. Democracia e a internet como esfera pública virtual: aproximação às condições da deliberação. In: GOMES, W.; MAIA, R. C. M. Comunicação e democracia: problemas e perspectivas. São Paulo: Paulus, 2008. p. 277-292.

MARQUES, F. P. J. A. Participação política e internet: meios e oportunidades digitais de participação civil na democracia contemporânea, com um estudo do caso do estado brasileiro. 2008. 498 f. Tese (Doutorado em Comunicação Social) - Universidade Federal da Bahia, Salvador, 2008.

MIN, S. Online vs. face-to-face deliberation: effects on civic engagement. Journal of Computer-Mediated Communication, v. 12, n. 4, p. 1369-1387, 2007.

OBLAK, T. Dialogue and representation: communication in the electronic public sphere. Javnost/The Public, v. 9, n. 2, p. 7-22, 2002.

PATEMAN, C. Participação e teoria democrática. Rio de Janeiro: Paz e Terra, 1992.

PEIXOTO, T. E-participatory budgeting: e-democracy from theory to success? E-Working Papers, set. 2008. Disponível em: $<$ http://edc.unige.ch/edcadmin/images/ Tiago.pdf $>$. Acesso em: 10 abr. 2009.

SALTER, L. Structure and forms of use: a contribution to understanding the 'effects' of the internet on deliberative democracy. Information, Communication \& Society, v. 7, n. 2, p. 185-206, 2004.

SAMPAIO, R. C. Diferentes modos de participação: alguns impactos da introdução da internet no Orçamento Participativo de Belo Horizonte. Comunicação \& Política, v. 27, n. 2, p. 51-78, 2009.

STEFFEN, C. A política nos espaços digitais: a campanha presidencial de 2002 na internet. 2004. 341 f. Dissertação (Mestrado em Ciências da Comunicação) Universidade do Vale do Rio dos Sinos, 2004.
TEORELL, J. Political participation and three theories of democracy: a research inventory and agenda. European Journal of Political Research, v. 45, n. 5, p. 787-810, 2006.

VERBA, S.; ORREN, G. R. Equality in America: the view from the top. Cambridge, MA: Harvard University Press, 1985.

WRIGHT, S.; STREET, J. Democracy, deliberation and design: the case of online discussion forums. New Media, v. 9, n. 5, p. 849-869, 2007.
Recebido: 26/03/2010

Received: 03/26/2010

Aprovado: 02/04/2010

Approved: 04/02/2010 